\title{
EMPREGO (E NÃO EMPREGO) DE DETERMINANTES EM TEXTOS ESCRITOS POR SURDOS ${ }^{80}$
}

\author{
PRESENCE OR ABSENCE OF DETERMINERS IN TEXTS WRITTEN BY DEAF \\ INDIVIDUALS
}

\author{
Dayane Celestino de Almeida ${ }^{81}$ \\ Deisieli Mirela Libralão de Araújo ${ }^{82}$
}

\begin{abstract}
RESUMO: O objetivo deste trabalho foi investigar quais fatores linguísticos e extralinguísticos regem a variação entre o Emprego e o Não Emprego de Determinantes em contextos em que o Emprego seria obrigatório em Português. Observaram-se 40 redações de 40 indivíduos Surdos que apresentam a Libras como L1 e o Português na modalidade escrita como L2. Partiu-se da premissa de que a produção textual escrita em Português de grande parte dos Surdos ainda está em estágio de "interlíngua". Seguiu-se o quadro teórico metodológico da Sociolinguística Variacionista. Formularam-se duas hipóteses: a primeira é a hipótese de que variante "adequada" (Emprego de Determinante) seria própria do Português e a variante "inadequada" (Não Emprego de Determinante) seria uma influência da Libras; a segunda é a hipótese de que a variação também é determinada pela influência de outros fatores, internos ao sistema linguístico, e não somente pela L1. Os resultados indicam que, quanto aos fatores extralinguísticos, o Não Emprego de Determinantes é desfavorecido quando os indivíduos adquiriram a Libras entre 6 e 12 anos de idade, e quando eles apresentam nível de Escolaridade Superior; quanto ao fatores linguísticos, os resultados nos mostram que o Não Emprego é favorecido quando o núcleo do sintagma apresentar o traço [- Humano] (e não o [+ Humano]) e quando estiver no Singular (e não no Plural). Os resultados indicam que a variação no emprego dos determinantes em Português escrito por Surdos é sistemática e motivada, e não simplesmente fruto do acaso ou de um erro resultante intrinsecamente da condição da surdez, o que é um mito frequente entre os leitores da escrita de Surdos.
\end{abstract}

Palavras-chave: Bilinguismo de Surdos; variação sociolinguística; determinantes.

ABSTRACT: The aim of this study was to investigate which linguistic and non linguistic factors govern the variation between the Presence or the Absence of determiners in contexts where the Presence would be mandatory in Portuguese. We have observed 40 essays, by 40 Deaf individuals that have Libras (Brazilian Sign Language) as L1 and written Portuguese as L2. The theoretical and methodological basis was Variationist Sociolinguistics and we have followed the assumption that the texts written by most Deaf bilinguals is still in a interlanguage stage. Two hypotheses were laid down: the first is that the "adequate" variant (the Presence of the Determiners) would be rooted in Portuguese and the "inadequate" variant (the absence) would come from Libras (the L1); the second is that variation is also determined by the influence of other factors, internal to the linguistic system, and not only by the L1. The results indicate that, as far as extralinguistic factors are concerned, the Absence of Determiners is disfavored when individuals acquired Libras between 6 and 12 years of age, and when they have higher level of education. As for linguistic factors, the results show that Absence is favored when the nucleus of the phrase has the trait [- Human] (not the [+ Human]) and when it is Singular (not Plural). The results indicate that this variation in deaf Portuguese is systematic and motivated, and not simply the result of chance, nor an error linked intrinsically to the condition of deafness, which is a frequent myth among readers of deaf writing.

Keywords: Deaf bilingualism; sociolinguistic variation; determiners.

\section{Introdução}

Este trabalho apresenta os resultados da análise de 40 redações de 40 indivíduos Surdos, em termos de variação entre o Emprego ou o Não Emprego de Determinantes no Sintagma Nominal (doravante SN), em contextos em que o Emprego seria obrigatório em Português. Tais

80 Este trabalho faz parte do Projeto intitulado Variação Sociolinguística no Português Escrito por Surdos, financiado pela FAPESP: Fundação de Amparo à Pesquisa do Estado de São Paulo, Processo nr. 2017/07032-6.

${ }^{81}$ Doutora em Linguística pela Universidade de São Paulo-USP. Professora do Departamento de Linguística Aplicada do Instituto de Estudos da Linguagem da UNICAMP.

${ }^{82}$ Aluna do curso de Letras da Universidade Estadual de Campinas, UNICAMP, Brasil. Bolsista do Projeto "Variação Sociolinguística no Português Escrito por Surdos", financiado pela Fapesp. 
participantes são considerados bilíngues, segundo a definição de "bilinguismo de Surdos" ${ }^{\text {"83 }}$ em que indivíduos apresentam uma língua de sinais como L1 (neste caso, a Libras - Língua Brasileira de Sinais) e a língua majoritária do país em que se inserem, na modalidade escrita, como L2 (neste caso, o Português).

O interesse em verificar o fenômeno aqui relatado (que é frequentemente apontado como uma característica do Português como L2 de Surdos por aqueles que travam contato com seus textos e por pesquisa, tais como, e.g., BROCHADO, 2003; LESSA-DE-OLIVEIRA e LOPES, 2017; LIMA-SALLES e VIANNA, 2010), do ponto de vista da variação linguística, é investigar que fatores influenciam essa variação.

A pesquisa em que esta análise se insere parte da premissa de que a produção textual em Português de grande parte dos Surdos ainda está em estágio de "interlíngua", isto é, um sistema híbrido que manifesta traços tanto da primeira língua (L1) do indivíduo quanto da sua língua-alvo (SELINKER, 1972). Sendo assim, a hipótese é que a variante ${ }^{84}$ "adequada" ("Emprego de Determinante", exemplificada em 1, abaixo) seria própria do Português e a variante "inadequada" ("Não Emprego de Determinante", exemplificada em 2, abaixo) seria uma influência da Libras. Os exemplos foram retirados do corpus analisado:

1. "O homem trabalha na rural".

2. "[Ele] viu pera na mão".

Parte-se, também, do pressuposto de que interlínguas e segundas línguas variam tanto quanto as línguas maternas (BAYLEY, 2007; REGAN, 2013) e obedecendo aos mesmos princípios, dentre eles o "princípio de múltiplas causas" (BAYLEY, 2002), que afirma que é improvável que um único fator seja motivador da variação observada. A análise multivariada vê cada ocorrência de uma variável (cada "variante") como "uma função de várias forças simultâneas, interseccionadas e independentes” (GUY e ZILLES, 2007, p. 50). Assim, outros fatores (e não somente a L1) que podem reger a variação linguística neste caso são considerados nesta análise, norteada pela sociolinguística variacionista, quadro teórico e metodológico que postula que tanto fatores sociais quanto linguísticos (também denominados externos/extralinguísticos ou internos/intralinguísticos, respectivamente) podem se associar a ou motivar o uso de uma ou outra variante linguística (e.g. CHAMBERS, 1995; CHAMBERS, TRUDGILL e SCHILLING-ESTES, 2001; LABOV, 1972, 1966; TRUDGILL, 1974; ).

Os fatores observados serão descritos mais adiante na seção de Metodologia, em que também se fala mais detidamente sobre o corpus analisado e sua constituição ${ }^{85}$.

Este trabalho pode demonstrar que a variação existente no Português de Surdos bilíngues (de novo, que tenham a Libras como L1 e o Português na modalidade escrita como L2) é sistemática, motivada e não aleatória (uma "heterogeneidade ordenada", para empregar as palavras de WEINREICH, LABOV e HERZOG, 1968) e não simplesmente fruto do acaso ou de um erro

83 Sobre o bilinguismo de Surdos, ver e.g. Ferreira-Brito, 1989; Goes, 2012; Kail, 2013; Lodi, Harrison e Campos, 2015.

Empregaos aqui os termos "variáveis" e "variantes" no sentido laboviano (LABOV, 1966, 1969). Dentro desse quadro teórico, o conjunto de duas ou mais formas de se dizer "a mesma coisa", isto é, duas ou mais formas linguísticas que veiculam um mesmo sentido em uma dada língua é chamado de variável linguística (mais especificamente, variável dependente). Essas diferentes formas são, por sua vez, chamadas de variantes. A variável linguística é, portanto, um conjunto de duas ou mais variantes.

85 Vale ressaltar que este trabalho faz parte de um projeto maior em que se analisam mais outras 3 variáveis linguísticas, a saber:

a) emprego ou omissão das preposições "em", "para" e "de";

b) realização ou não realização da concordância nominal de número;

c) realização ou não realização da flexão verbal; 
resultante intrinsecamente da condição da surdez, o que é um mito frequente não só para este fenômeno linguísticos, mas para várias outros.

\section{Metodologia e definição das variáveis e variantes}

Como mencionado na Introdução, os dados para este estudo foram extraídos de 40 textos redigidos por 40 participantes Surdos. Tais participantes foram selecionados segundo os seguintes critérios: i) ter aprendido Libras até 12 anos de idade ${ }^{86}$; ii) ser bilíngue, ou seja, empregar o Português Escrito como L2 e escrever com relativa frequência; e iii) ter entre 15 e 35 anos de idade.

Os textos baseiam-se no filme "Estória da Pêra" ${ }^{87}$ (CHAFE, 1980; aproximadamente 6 min., sem falas). Aos participantes, solicitou-se assistir ao filme e em seguida escrever um texto narrativo o mais detalhadamente possível contando a estória vista. As redações foram coletadas e posteriormente transcritas e salvas em formato .txt para facilitar a manipulação dos dados em meios digitais.

A amostra está estratificada segundo os seguintes fatores (8 perfis de informantes, 5 informantes por perfil $)^{88}$ :

1) Idade de Aquisição da Libras (Até 5 anos de idade / De 6 a 12 anos);

2) Exposição à Terapia de Oralização/Habilidades em Leitura Labial (Oralizado / Não Oralizado);

3) Nível de Escolaridade (Ensino Médio / Ensino Superior).

Foram exatamente esses fatores os considerados como "fatores externos" na análise, que teve o intuito de testar se eles se correlacionam com o Emprego ou não dos Determinantes. Os dois primeiros grupos de fatores estão evidentemente associados à possível influência da L1 na L2, ou da influência de um input incompleto como é o caso da Terapia de Oralização.

Chama a atenção o fato de que o segundo grupo de fatores, que trata da Oralização e das Habilidades de Leitura Labial, é, na verdade, uma categorização que levou em conta não só se o indivíduo surdo de fato oraliza ou se tem uma boa habilidade de Leitura Labial, mas também se fez terapia de oralização por mais de dois anos e antes dos 12 anos de idade ${ }^{89}$.

O grupo de fatores Escolaridade, por sua vez, não está ligado intimamente ao fenômeno de transferência linguística, mas é relevante neste caso já que se espera que uma maior Escolaridade leve o indivíduo a escolher mais regularmente variantes padrão. A pressão exercida pela escola

86 A idade máxima de 12 anos foi adotada observando-se o período crítico para aquisição de linguagem de Lenneberg (1967), já que se pretende verificar se há transferência da L1 para L2. Além disso, vale a pena ressaltar que todos os falantes possuem a Libras como L1, no sentido de "língua de conforto", mesmo que a tenham aprendido mais tardiamente.

87 O filme pode ser assistido aqui: https://www.youtube.com/watch?v=bRNSTxTpG7U. Acesso em 01/06/2019.

88 Essas informações foram obtidas por meio de uma "Ficha do Participante", entregue no momento da coleta de dados e preenchida pelo participante sob a supervisão de um documentador.

89 Foi classificado como "Oralizado" o indivíduo que foi considerado "Positivo" em pelo menos duas das três perguntas abaixo, que constavam da Ficha do Informante:

a) Fez terapia de oralização?

b) Com quantos anos de idade iniciou a terapia de oralização?

c) Numa escala de 0 a 5 , qual você acha que é o seu grau de leitura labial?

Para ser considerado "Positivo", informante deveria ter assinalado:

a) Na pergunta 1: "Sim, por 2 a 5 anos" ou "Sim, por 6 anos ou mais".

b) Na pergunta 2: "Antes dos 6 anos de idade" ou "Entre 7 e 12 anos de idade".

c) Na pergunta 3: "3", ou "4", ou "5". 
170 | Dayane Celestino de Almeida, Deisieli Mirela Libralão de Araújo

poderia levar o indivíduo a empregar mais consistentemente a forma tida como própria do Português do que aquela possivelmente associada à sua língua materna.

Além dos três grupos de fatores que estratificam a amostra (chamado de "sociais" ou "externos"), foram observados também os seguintes fatores linguísticos (também chamados de "internos", selecionadas a partir de uma análise qualitativa dos dados:

1) "Humanidade" no núcleo do $\mathrm{SN}$ :

a) traço [+ Humano].

Exemplo: "Havia um homem que colher frutas".

b) traço [- Humano].

Exemplo: "João levou muitas pêras".

2) Número do SN:

a) Singular.

Exemplo: "Havia um homem que colher frutas".

b) Plural.

Exemplo: "Os meninos andar com bicileta".

3) Modificador do Núcleo do Sintagma:

a) Com Modificador.

Exemplo: "ai caixa de frutas caiu".

b) Sem Modificador.

Exemplo: "Um homem estava em cima da ávores".

4) Paralelismo:

a) Primeiro Da Série ${ }^{90}$.

Exemplo: "Um homem estava em cima da ávores pegando a pera".

b) Anterior Com Determinante.

Exemplo: "Um homem estava em cima da ávores pegando a pera".

c) Anterior Sem Determinante.

Exemplo: "Enquanto homem estaria trabalhando uma fazenda".

Com as redações já transcritas, passou-se à análise de cada ocorrência do fenômeno, etiquetando-as como "Com Determinante" ou "Sem Determinante" e também de acordo com as variantes $^{91}$ das variáveis linguísticas e sociais. Para isso, foi utilizado o software "UAM-CorpusTool" (O’DONNELL, 2012), com adaptações realizadas para tal tarefa. Findo o processo de codificação (ou etiquetação), exportaram-se os dados deste sistema para uma planilha em formato ".csv" que foi importada no programa R (R CORE TEAM, 2013), em que foram feitas as análises estatísticas. O $\mathrm{R}$ tem sido mais recentemente utilizado com sucesso em análises quantitativas em sociolinguística, anteriormente dominadas pelo Varbrul (CEDERGREN; SANKOFF, 1974). Para vantagens na sua utilização nesse tipo de análise, ver Oushiro (2015).

90 Uma série corresponde a uma sequência de quatro SNs, sejam eles com presença ou não de Determinantes.

91 Empregaram-se os termos "variáveis" e "variantes" de acordo com a Sociolinguística variacionista que por sua vez empresta os termos da Estatística. A variável linguística sob análise é uma "variável dependente”. As variáveis linguísticas ou não linguísticas que podem ou não influenciar a variação são as "variáveis independentes". Tanto variáveis dependentes quanto independentes são compostas por variantes. As variáveis independentes também são chamadas, em sociolinguística, de grupos de fatores, e as suas variantes, de fatores. 
A partir do R, foram calculadas as proporções do Emprego versus Não Emprego de Determinantes por cada variante das variáveis independentes, verificando-se se existia ou não uma diferença estatisticamente significativa entre essas proporções. Em seguida, foi realizada uma análise multivariada, isto é, verificou-se, quais fatores favorecem ou desfavorecem o Não Emprego (variante estigmatizada), quando considerados em conjunto e não isoladamente. Para a análise multivariada das correlações empregou-se um modelo de regressão logística. Um panorama da distribuição dos dados e os resultados dessas análises são apresentados na próxima seção.

\section{Análises e Resultados}

Foram encontradas 992 ocorrências da variável dependente sob análise, sendo que 655 delas (66\%) correspondem ao Emprego de Determinante e 337 (34\%) ao Não Emprego, conforme mostra a Tabela 1 a seguir:

Tabela 1: Distribuição da Variável Dependente

\begin{tabular}{|c|c|c|}
\hline Com Determinante & Sem Determinante & TOTAL \\
\hline 655 & 337 & 992 \\
\hline $66 \%$ & $34 \%$ & $100 \%$ \\
\hline
\end{tabular}

O foco da análise que se seguiu foi o Não Emprego. A primeira coisa a reparar é o fato de que a frequência de uso desta variante é bem menor do que a da variante Emprego, e isto é interessante justamente porque vai contra muitos comentários do senso comum, no sentido de que "os Surdos não usam artigos" (como se isso fosse algo categórico). Ora, não só não é categórico, como ainda ocorre em uma proporção muito menor, ao menos nesse corpus.

Passou-se, então, à verificação das proporções dentro de cada grupo de fatores. Quando se olhou para a Faixa Etária de Aquisição da Libras, vê-se que a diferença entre a primeira faixa etária de aquisição e a segunda é significativa ${ }^{92}$ (Cf. Tabela 2, a seguir), sendo que a proporção de Não Emprego de Determinantes é maior dentre os indivíduos que adquiriram Libras na primeira infância, ou seja, dentre aqueles que teriam a Libras adquirida numa fase considerada menos crítica para aquisição de L1, sendo portanto indivíduos que já teriam a língua de sinais mais consolidada, o que nos faz supor que a hipótese de transferência linguística parece se confirmar.

Tal hipótese ganha força quando se observaram os dados do segundo grupo de fatores, o das Habilidades de Oralização/Leitura Labial (também verificar Tabela 2). Indivíduos que foram codificados como "Não Oralizados" (ou seja, com menos habilidades de Oralização e Leitura Labial) tem uma proporção ligeiramente maior (mas estatisticamente significativa) da variante "Não Emprego", ou seja, nestes indivíduos permanece a influência da L1 que não foi de modo algum substituída pelo input fornecido pelos processos de oralização (veja que a proporção de Emprego de Determinantes é maior entre os Oralizados).

Por último, dentre os fatores sociais, vê-se que, no caso da Escolaridade, a diferença entre o Ensino Médio e Ensino Superior é bastante significativa (ver Tabela 2), sendo que a proporção de Não Emprego é muito maior entre os de menor nível de Escolaridade, evidenciando a importância da continuidade desses sujeitos no ambiente educacional para uma maior proficiência do Português como L2.

92 Lembrando que a diferença foi considerada significativa quando o valor de p < 0,05 ( Teste de Qui Quadrado). 
Tabela 2: Distribuição das variáveis sociais

\begin{tabular}{|c|c|c|c|c|c|c|c|}
\hline & & Com Deter. & $\%$ & $\begin{array}{l}\text { Sem } \\
\text { Deter. }\end{array}$ & $\%$ & Total & $p$ value \\
\hline \multirow{2}{*}{$\begin{array}{l}\text { FAIXA ETÁRIA DE } \\
\text { AQUISIÇÃAO DA } \\
\text { LIBRAS }\end{array}$} & $\begin{array}{l}\text { Primeira (Até } 5 \\
\text { anos) }\end{array}$ & 254 & 53,8 & 218 & 46,2 & 472 & \multirow{2}{*}{$1.695 \mathrm{e}-14$ * } \\
\hline & $\begin{array}{l}\text { Segunda (De } 6 \text { a } \\
12 \text { anos) }\end{array}$ & 401 & 77,1 & 119 & 22,9 & 520 & \\
\hline \multirow[t]{2}{*}{$\begin{array}{l}\text { ORALIZAÇÃO \& } \\
\text { LEITURA LABIAL }\end{array}$} & Não Oralizado & 281 & 62,2 & 171 & 37,8 & 452 & \multirow{2}{*}{$0.02253^{*}$} \\
\hline & Oralizado & 374 & 69,3 & 166 & 30,7 & 540 & \\
\hline \multirow[t]{2}{*}{ ESCOLARIDADE } & Médio & 191 & 45,4 & 230 & 54,6 & 421 & \multirow{2}{*}{$<2.2 \mathrm{e}-16^{*}$} \\
\hline & Superior & 464 & 81,3 & 107 & 18,7 & 571 & \\
\hline
\end{tabular}

A partir desses resultados, pode-se dizer que a Idade de Aquisição (evidenciando que há transferência linguística) e a Escolaridade têm influência sobre a variável em questão, resultado que se confirma em termos de correlações que despontam quando se consideram outros fatores (os linguísticos) em conjunto, como será mostrado mais adiante.

Passando à distribuição dos dados dentro dos grupos de fatores linguísticos, verificou-se que, com relação às diferenças das proporções dos fatores dentro de cada grupo, todos eles se mostraram significativos em termos estatísticos. A Tabela 3 (a seguir), apresenta os resultados:

Tabela 3: Distribuição das variáveis linguísticas

\begin{tabular}{|c|c|c|c|c|c|c|c|}
\hline & & $\begin{array}{l}\text { Com } \\
\text { Deter. }\end{array}$ & $\%$ & $\begin{array}{l}\text { Sem } \\
\text { Deter. }\end{array}$ & $\%$ & TTotal & $p$ value \\
\hline \multirow[t]{2}{*}{ NÚMERO } & Plural & 175 & 87,1 & 26 & 12,9 & 201 & \multirow{2}{*}{$-3.2 \mathrm{e}-12$ * } \\
\hline & Singular & 480 & 60,7 & 311 & 39,3 & 791 & \\
\hline \multirow[t]{2}{*}{ HUMANID. DO SN } & [+ Humano] & 323 & 71,3 & 130 & 28,7 & 453 & \multirow{2}{*}{-0.001643 * } \\
\hline & [-Humano] & 332 & 61,6 & 207 & 38,4 & 539 & \\
\hline \multirow[t]{2}{*}{ MODIFICADOR } & Sem Modificador & 597 & 68,3 & 277 & 31,7 & 874 & \multirow{2}{*}{$5.818 \mathrm{e}-05$} \\
\hline & Com Modificador & 58 & 49,2 & 60 & 50,8 & 118 & \\
\hline PARALELISMO & Primeiro Da Série & 176 & 67,7 & 84 & 32,3 & 260 & $<2.2 \mathrm{e}-16 *$ \\
\hline
\end{tabular}


Emprego (e não emprego) de determinantes em textos escritos por surdos | 173

\begin{tabular}{|lllllll}
\hline $\begin{array}{l}\text { Anterior Com } \\
\text { Determ. }\end{array}$ & 391 & 80,3 & 96 & 19,7 & $\mathbf{4 8 7}$ \\
\hline $\begin{array}{l}\text { Anterior Sem } \\
\text { Determ. }\end{array}$ & 88 & 35,9 & 157 & 64,1 & $\mathbf{2 4 5}$ \\
\hline
\end{tabular}

* Diferença Significativa (teste de Qui Quadrado)

O Não Emprego de Determinantes é maior em SNs que estejam no Singular, que tenham núcleo com o traço [- Humano], que apresentem um Modificador e que estejam seguindo um SN que também não tenha apresentado o Determinante.

Apesar das diferenças entre as proporções para todos esses grupos serem significativas, cabe verificar se quando considerados em conjunto, num modelo de regressão logística eles se mantêm relevantes em termos de favorecimento do Não Emprego de Determinantes. Em outras palavras, existe correlação entre quais fatores e o Não Emprego?

O primeiro modelo de regressão logística considerado para responder a essa questão incluiu todos os 7 grupos de fatores ( 3 sociais e 4 linguísticos) presentes no estudo. A seguir encontram-se os resultados entregues pelo programa R (Quadro 1). Não cabe nos limites deste artigo explicar ou detalhar cada output fornecido pelo software (para detalhes ver OUSHIRO, 2017), mas sim mostrar que os fatores com os asteriscos foram considerados significativos, ou seja, eles favorecem ou desfavorecem as características linguísticas observadas (dito de outro modo: eles se correlacionam a elas). O que nos interessa aqui é a coluna "Estimate". Ela traz valores numa escala com números positivos a negativos. Os valores positivos indicam tendência ao favorecimento em relação ao outro nível da mesma variável. Por exemplo, na linha três, há o grupo Escolaridade, seguida da letra S que aqui é o código para "Ensino Superior". O que se vê é que o valor de "Estimate" nesta linha é 1,5131 ou seja, o fator "Ensino Superior" desfavorece o Não Emprego de Determinante (que é, sempre, a variante em foco), em relação ao "Ensino Médio". Veja-se o Quadro 1 abaixo, com os valores de todos os fatores:

Quadro 1: Correlações entre grupos de fatores e a variável dependente: modelo de regressão logística

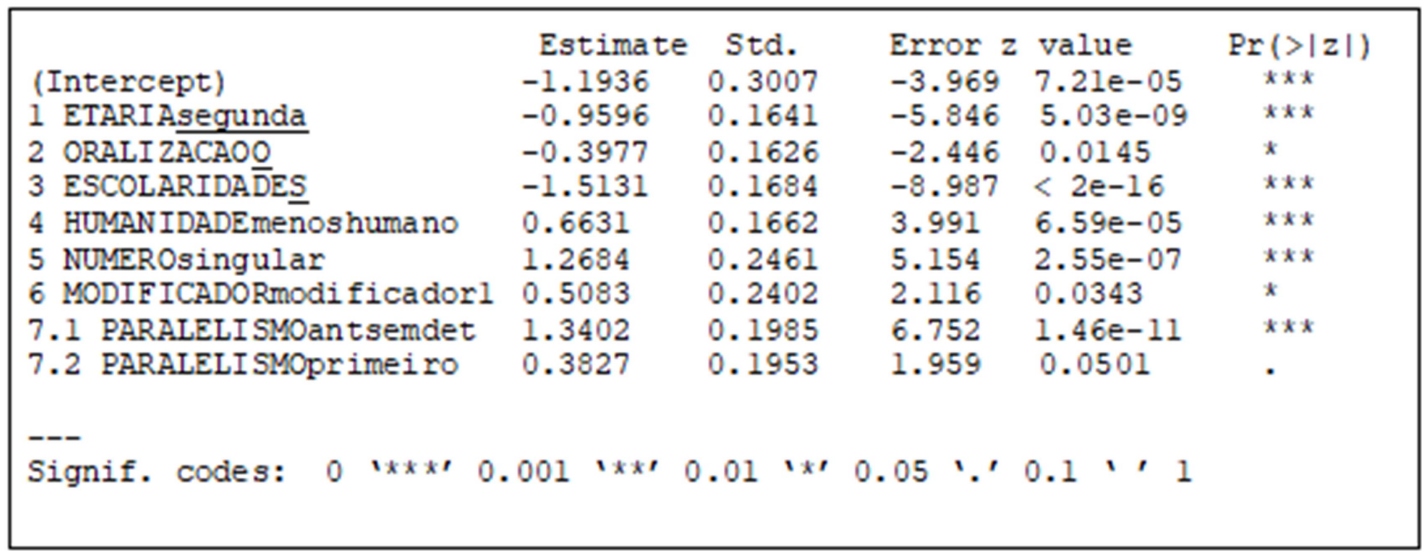

Os resultados podem ser colocados da seguinte forma, dividos em "1" e "2", a seguir:

1) O Não Emprego de Determinantes é desfavorecido pelos fatores:

a) Segunda Faixa Etária de Aquisição de Libras;

b) Habilidade de Oralizar/Fazer Leitura Labial;

c) Escolaridade Superior. 
Em outras palavras, indivíduos que tenham aprendido a Libras mais tardiamente, que sejam mais Oralizados ${ }^{93}$ ou façam melhor Leitura Labial, e com maior nível de Escolaridade tendem a empregar mais a variante padrão (realizar o Determinante) em relação àqueles que tenham a Libras consolidada como L1 ainda na primeira infância, que não tenham habilidades orais ou de Leitura Labial (dois fatores que se relacionam à influência da L1 na L2) e com nível de Escolaridade até o Ensino Médio. Esses resultados se coadunam com a análise de proporções apresentada anteriormente.

2) O Não Emprego de Determinantes é favorecido, quando:

a) O núcleo do sintagma apresentar o traço [- Humano] (e não o [+ Humano]);

b) O núcleo do sintagma estiver no Singular (e não no Plural);

c) O núcleo do sintagma aparecer seguido de um Modificador (e não sozinho);

d) Houver Paralelismo, ou seja, quando o sintagma anterior também não empregar o Determinante.

Há algumas observações com relação a tais resultados, que nos mostram o encaixamento estrutural da variação. Em primeiro lugar, ressalta-se que em outro trabalho sobre a variação no Português de Surdos, integrante do mesmo projeto do qual este estudo faz parte, Almeida e Hanada (2019) observaram que o "Núcleo do SN com o traço semântico [- Humano] favorece o emprego da Não Concordância". Ou seja, tanto lá quanto aqui, a variante considerada inadequada está sendo favorecida pelo mesmo traço semântico. É interessante também notar que nos dois casos as variantes sob análise são do tipo "presença ou ausência" de um elemento (morfema de plural realizado ou não; Determinante realizado ou não).

Semelhanças com outros resultados se encontram no que diz respeito ao Paralelismo (item d). Um SN Sem Determinante favorece o aparecimento de outro na mesma condição, analogamente ao que foi visto por Almeida e Hanada (2019), em que não concordância favorece não concordância - o fenômeno descrito por Scherre (1988) como "paralelismo formal".

O favorecimento do Não Emprego de Determinantes quando existe um Modificador (adjetivo, locução adjetiva) acompanhando o núcleo do sintagma, ou seja, a presença de um elemento dentro do sintagma favorecendo a não presença de outro, poderia ser encarado, talvez, como evidência de uma certa "economia" em ação, análoga ao princípio funcional de economia (HAIMAN, 1983). Se existe já um elemento que atua sobre o núcleo (o modificador), não haveria a necessidade de outro (o Determinante).

Voltando aos resultados resumidos em "1", pode-se ir além na nossa observação realizando o cruzamento entre os fatores "Faixa Etária de Aquisição da Libras" e "Habilidade de Oralizar/Fazer Leitura Labial. Quando se observam as faixas etárias isoladamente, vê-se que, nas duas faixas, a proporção maior é sempre a de Emprego de Determinante. Ou seja, de modo geral, independentemente da faixa etária, mais indivíduos empregam o Determinante do que não empregam (voltar à Tabela 1). No entanto, quando se cruzaram os dados (ver Tabela 4), a situação se inverte, apenas dentro da Primeira Faixa Etária, quando considerados somente os indivíduos Não Oralizados nesta faixa. Observe-se também que proporção de Não Emprego no cruzamento "Primeira + Não Oralizado" é ligeiramente maior do que no cruzamento "Primeira + Oralizado". Isso pode nos levar à conclusão de que, de alguma forma, treinamentos de oralização podem barrar, mesmo que em uma pequena medida, a transferência linguística desse fenômeno em indivíduos que tenham a Libras mais consolidada como L1.

93 Lembrando que não se trata de realmente empregar a língua oral, mas da combinação de fatores explicada anteriormente. 
Tabela 4: Cruzamento entre os fatores "Faixa Etária de Aquisição da Libras" e "Habilidade de Oralizar/Fazer Leitura Labial

\begin{tabular}{|c|c|c|c|c|c|c|}
\hline $\begin{array}{l}\text { FAIXA ETÁRIA } \\
\text { DE AQUISIÇÃO }\end{array}$ & $\begin{array}{l}\text { HABILIDADES DE } \\
\text { ORALIZAÇÃO / } \\
\text { LEITURA LABIAL }\end{array}$ & $\begin{array}{l}\text { Com } \\
\text { Determinante }\end{array}$ & $\%$ & $\begin{array}{l}\text { Sem } \\
\text { Determinante }\end{array}$ & $\%$ & Total \\
\hline \multirow[t]{2}{*}{ PRIMEIRA } & NÃO ORALIZADO & 103 & $46,8 \%$ & 117 & $53,2 \%$ & 220 \\
\hline & ORALIZADO & 151 & $59,9 \%$ & 101 & $40,1 \%$ & 252 \\
\hline \multirow[t]{2}{*}{ SEGUNDA } & NÃO ORALIZADO & 178 & $76,7 \%$ & 54 & $23,3 \%$ & 232 \\
\hline & ORALIZADO & 223 & $77,7 \%$ & 64 & $22,3 \%$ & 287 \\
\hline
\end{tabular}

O segundo passo da análise de correlações foi criar um modelo de regressão que considerasse também cada um dos participantes, como variável de efeito aleatório. As variáveis linguísticas ou sociais que haviam sido analisadas até o momento são variáveis de efeito fixo, isto é, "cujos exemplares da amostra são representativos da população amostrada" e "podem ser replicados em outros estudos" (OUSHIRO, 2015, p. 56). "Informante" é uma variável de efeito aleatório porque é uma variável específica da amostra analisada (OUSHIRO, 2015). A importância desses modelos de efeitos mistos é que "a inclusão de efeitos aleatorios no modelo estatistico permite verificar se as correlaçôes observadas se devem aos efeitos fixos ou se possivelmente se devem à contribuição casual de certos indivíduos ou itens lexicais que eventualmente se comportam de modo distinto da população em geral" (OUSHIRO, 2015, p. 56). Johnson (2009) afirma que, nesses modelos, uma variável independente só vai ser selecionada como relevante estatisticamente se as correlações forem fortes o suficiente para superar a variação em cada informante (e, por extensão, em cada item lexical).

Quando incluímos, então, em nossa análise, a variável "Informante" como efeito aleatório, as variáveis Habilidades de Oralização/Leitura Labial, Modificador e Paralelismo deixam de ser significativas, isto é, não são suficientemente correlacionadas ao fenômeno de um ponto de vista geral, conforme se vê no output do R (Quadro 2), a seguir (variáveis significativas em negrito):

Quadro 2: Correlações entre grupos de fatores e a variável dependente: modelo de regressão logística com variável "Informante" como efeito misto.

\begin{tabular}{|c|c|c|c|c|c|}
\hline $\begin{array}{l}\text { (Intercept) } \\
1 \text { ETARIAsegunda }\end{array}$ & $\begin{array}{l}\text { Estimate } \\
-0.65737 \\
-1.32469\end{array}$ & $\begin{array}{l}\text { Std. Error } \\
0.54531 \\
0.46974\end{array}$ & $\begin{array}{l}z \text { value } \\
-1.206 \\
-2.820\end{array}$ & $\begin{array}{l}\operatorname{Pr}(>|z|) \\
0.228009 \\
0.004802\end{array}$ & $\star \star$ \\
\hline $\begin{array}{l}2 \text { ORALI ZACAOO } \\
3 \text { ESCOLARIDS }\end{array}$ & $\begin{array}{l}-0.57398 \\
-1.78062\end{array}$ & $\begin{array}{l}0.46685 \\
0.47131\end{array}$ & $\begin{array}{l}-1.229 \\
-3.778\end{array}$ & $\begin{array}{l}0.218897 \\
0.000158\end{array}$ & $\star \star \star \star$ \\
\hline 4 HUMANIDADE $\bar{E}-$ humano & 1.00869 & 0.19104 & 5.280 & $1.29 e-07$ & $\star \star \star$ \\
\hline 5 NUMEROsing & 1.18521 & 0.27030 & 4.385 & $1.16 \mathrm{e}-05$ & $\star \star \star$ \\
\hline 6 MODIFICADORmodi ficador 1 & 10.53114 & 0.27744 & 1.914 & 0.055560 & - \\
\hline 7.1 PARALELI SMOsn tsemdet & 0.41385 & 0.23529 & 1.759 & 0.078592 & - \\
\hline $\begin{array}{l}\text { T.2 PARALELISMOprImEI YO } \\
---\end{array}$ & -0 & $0.224 / 5$ & -0.236 & 0.81 & \\
\hline
\end{tabular}

\section{Considerações Finais}

Conforme delineado na Introdução, este trabalho teve o objetivo de entender como a variação entre o Emprego ou Não Emprego de Determinantes se organiza na produção escrita de 
indivíduos Surdos. Verifica-se que o Não Emprego de Determinantes é desfavorecido pelos fatores:

a) Segunda Faixa Etária de Aquisição de Libras;

b) Habilidade de Oralizar/Fazer Leitura Labial;

c) Escolaridade Superior.

Dito de outro modo, participantes que adquiriram a Libras mais tarde, que têm melhores habilidades Orais e de Leitura Labial, e maior nível de Escolaridade tendem a empregar mais a variante considerada adequada (realizar o Determinante) em relação àqueles que tenham adquirido a Libras até os 5 anos de idade, que tenham menos ou nenhuma habilidade de Oralizar ou de fazer Leitura Labial e com nível de Escolaridade até o Ensino Médio.

No entanto, quando se considera cada participante no modelo estatístico, a Habilidade de Oralizar/Fazer Leitura Labial deixa de ser significativa, o que indica que provavelmente há indivíduos neste agrupamento que destoam do restante do grupo e a correlação observada não é forte o suficiente para superar essa discrepância.

Este resultado nos confirma que há uma influência da Libras sobre o Português Escrito, no caso dessa variável linguística, quando esta é de fato a L1 do indivíduo surdo, e que quanto maior a exposição ao Português Escrito, por meio da escola, maior a chance de produção de formas consideradas adequadas (as formas de prestígio) e próprias do Português. Por outro lado, as Habilidades Orais parecem não ter grande influência.

Contudo, a variação não é regida apenas por esses fatores, mas também por fatores linguísticos e, nesse âmbito, os resultados nos mostram que Não Emprego de Determinantes é favorecido, quando:

a) O núcleo do sintagma apresentar o traço [- Humano] (e não o [+ Humano]);

b) O núcleo do sintagma estiver no Singular (e não no Plural);

c) O núcleo do sintagma vier seguido de um Modificador (e não sozinho);

d) Houver Paralelismo, ou seja, quando o $\mathrm{SN}$ anterior também não empregar o Determinante.

Aqui também, quando incluídos os participantes no modelo estatístico, há uma redução dos grupos de fatores que apresentam uma correlação estatisticamente relevante com a variável dependente, permanecendo apenas a "Humanidade" do núcleo e o número do sintagma. Uma análise que examine mais detidamente essas variáveis linguísticas ainda precisa ser realizada e será tema de trabalhos futuros.

A partir desses resultados, podem-se fazer algumas afirmações que suplantam mitos frequentes que rondam a escrita dos Surdos, a ver:

- A escrita dos Surdos não é, pelo menos no caso desta variável, caótica como pode parecer em um primeiro momento, mas sim obedece a padrões de variação.

- O emprego da forma "inadequada" não ocorre devido a um problema intrínseco à surdez enquanto patologia ou a uma deficiência cognitiva do Surdo, mas sim das condições de exposição dos indivíduos Surdos à Libras ou ao Português, e também de uma possibilidade advinda da própria estrutura, do próprio sistema linguístico.

Além disso, saber quais fatores extralinguísticos influenciam a produção escrita dos Surdos pode direcionar Políticas Linguísticas para uma educação bilíngue de Surdos mais eficaz. E saber quais fatores intralinguísticos influenciam tal produção pode direcionar métodos de ensino do Português como L2; por exemplo, uma vez que se sabe que há uma tendência em não se empregar Determinantes em sintagmas que tenham um Modificador depois do núcleo, pode-se focar este ponto ao ensinar a língua, mostrando de modo mais enfático que mesmo que haja um contraste como "Com Modificador" versus "Sem Modificador", ainda assim é necessário colocar um Determinante antes do núcleo.

Esperamos ter lançado algumas luzes sobre a questão da variação sociolinguística do Português Escrito como L2 dos Surdos, mostrando o que ocorre no caso de apenas uma variável 
linguística, mas lançando também, com isso, uma semente, na esperança de que este trabalho instigue pesquisadores a buscar compreender o funcionamento de outros fenômenos variáveis neste Português.

\section{Referências}

ALMEIDA, D. C. Variação sociolinguística no Português escrito por Surdos. Projeto de Pesquisa. Unicamp/Fapesp, Campinas/São Paulo, 2017.

ALMEIDA, D.C; HANADA, L. Variação na concordância nominal de número em redações de Surdos. The Especialist. Dossiê sobre Bilinguismo de Surdos. No prelo, 2019.

BAYLEY, R. Second language acquisition: a variationist perspective. In: ; CELI, L. Sociolinguistic variation: theories, methods, and applications. New York: Cambridge University Press, 2007.

BAYLEY, R. The quantitative paradigm. In: CHAMBERS, J.K.; TRUDGILL, P; SCHILLINGESTES, N. (Eds.), The handbook of language variation and change, pp. 85-107. Malden, MA: Blackwell, 2002.

BRANDÃO, S.F.; VIEIRA, S.R. Concordância nominal e verbal: contribuições para o debate sobre o estatuto da variação em três variedades urbanas do Português. Alfa, vol. 56, pp. 1035-1064, 2012.

BROCHADO, S. D. A apropriação da escrita por crianças surdas usuárias da língua de sinais brasileira. Tese (Doutorado em Letras). Faculdade de Ciências e Letras de Universidade Estadual Paulista (UNESP) - Assis, 2013.

CEDERGREN, H. J.; SANKOFF, D. Variable rules: performance as a statistical reflection of competence. Language, vol. 50 (2), pp. 333-355, 1974.

CHAFE, W. The pear stories: cognitive, cultural and linguistic aspects of narrative production. Norwood, New Jersey: Alelix, 1980.

CHAMBERS, J. Sociolinguistic theory. Oxford: Blackwell, 1995.

CHAMBERS, J.; TRUDGILL, P.; SCHILLING-ESTES, N. The handbook of language variation and change. Oxford/Malden: Blackwell, 2001

FERREIRA-BRITO, L. Necessidade psicossocial e cognitiva de um bilinguismo para o

surdo. Trabalhos em linguística aplicada, número 14, pp. 89-100, 1989.

GOES, M. C. R. Linguagem, surdez e educação. Campinas: A. Associados, 2012.

GUY, G.; ZILLES, A. Sociolinguística quantitativa: instrumental de análise. São Paulo: Parábola, 2007.

HAIMAN, J. Iconic and economic motivation. Language, Vol. 59, No. 4 (Dec., 1983), pp. 781-819.

JOHNSON, D. E. Getting off the GoldVarb standard: introducing Rbrul for mixed-effects variable rule analysis. Language and Linguistics Compass, vol 3, pp. 359-383, 2009.

KAIL, M. Aquisição de linguagem. São Paulo: Parábola, 2013

KIESLING, S. Style as stance: stance as the explanation for patterns of sociolinguistic variation. In: JAFFE, A. (Org.). Stance: sociolinguistic perspectives. Oxford: Oxford University Press, 2009.

LABOV, W. The social stratification of English in New York City. São Paulo: Cambridge University Press, 1966.

LABOV, W. Contraction, deletion, and inherent variability of the English copula. Language, 45, pp. 715-762, 1969.

LABOV, W. Sociolinguistic patterns. Philadelphia: University of Pennsylvania Press, 1972.

LENNEBERG, E. H. Biological foundations of language. Neurology, 17, pp. 1219-1219, 1967.

LESSA-DE-OLIVEIRA, L.; LOPES, A. Desenvolvimento linguístico de Surdos adultos no ensino superior: aquisição de determinantes na escrita da L2. In: IX Seminário de Pesquisa e Estudos Linguisticos. Anais. Vol.9, n.1, 2017. 
LIMA-SAlLES, H.; VIANNA, A. Estudo da interlíngua de Surdos usuários de Língua de Sinais Brasileira na aquisição de Português (L2): nominais nus e definidos genéricos. Estudos da Lingua(gem). Vitória da Conquista v.8, n. 1, pp. 241-264, 2010

LODI, A. C.; HARRISON, K.; CAMPOS, S. R. Letramento e surdez: um olhar sobre as particularidades do contexto educacional. In: ; MELO, A.; FERNANDES, E. (Orgs.). Letramento, bilinguismo e educação de Surdos. Porto Alegre: Mediação, 2015.

LUCCHESI, D. A variação na concordância verbal no Português popular da cidade de Salvador. Estudos Linguísticos e Literários, n.52, ago-dez, Salvador: pp. 166-204, 2015.

O'DONNELL, M. UAM Corpus Tool, 2012. Disponível em <http://www.corpustool.com/download.html>. Acesso em 20 de maio de 2019.

OUSHIRO, L. Identidade na pluralidade: avaliação, produção e percepção linguística na cidade de São Paulo. Tese de Doutorado. São Paulo: Universidade de São Paulo, 2015.

OUSHIRO, L. Introdução à estatística para linguistas, v.1.0.1 (dez/2017). Disponível em <http://rpubs.com/oushiro/iel>. Acesso em 20 de maio de 2019.

R CORE TEAM. R: A language and environment for statistical computing. Vienna, 2013.

REGAN, V. Variation and second language acquisition. In: HERSCHENSON, J.; YOUNGSCHOlTEN, M. (Orgs.), The Cambridge handbook of second language acquisition, pp. 272-291. Cambridge: Cambridge University Press, 2013.

SCHERRE, M.M.P. Reanálise da concordância nominal em Português. Tese (Doutorado em Linguística). UFRJ - Rio de Janeiro: Dois volumes, 1988,

SCHERRE, M.M.P.; NARO, A. Mudança sem mudança: a concordância de número no Português brasileiro. SCRIPTA, vol 9, pp.107-129, 2006.

SELINKER, L. Interlanguage. International review of applied linguistics, 10, pp. 219-231, 1972.

TRUDGILL, P. The social differentiation of English in Norwich. Cambridge: Cambridge University Press, 1974.

WEINREICH, U.; LABOV, W.; HERZOG, M. Empirical foundations for a theory of language change. In: Lehmann, W.; Malkiel, Y. (Orgs.). Directions for Historical Linguistics, a symposium, pp. 95-195. Austin: Universit.

Recebido em: 16/08/19

Aceito em: 18/11/19 